\title{
A AFIRMAÇÃO COMO FUNDAMENTO BASILAR DA AXIOLOGIA
}

Jorge Jaime*

SÍNTESE - O autor defende a teoria da afirmação pura de Patricio Muniz contra os ataques de Leonel Franca e Silvio Romero e sustenta que a teoria é parte integrante da Axiologia.
ABSTRACT - The author defends Patricio Muniz's theory of affirmation against Leonel Franca and Silvio Romero's and sustains that the theory is an integrated part of Axiology.

Procuraremos analisar a idéia de afirmação, basilar para o entendimento da Axiologia como futura ciência positiva.

Embora tenha, no correr do meu meditar sobre os problemas axiológicos, chegado à necessidade de estabelecer a afirmação como fundamento dessa nova ciência, esta idéia não é recente, uma vez que, ao estudar os pensadores antigos do Brasil, encontrei o estudo do padre Patrício Muniz, cuja principal obra foi, certamente, a sua tão mal compreendida Teoria da afirmação pura (Rio, 1863). Sílvio Romero, que foi aluno desse português nascido na ilha da Madeira em 1820 e, posteriormente, naturalizado brasileiro, confessou ter recebido do seu mestre alguma influência. Todavia, não o compreendeu, tendo feito críticas ferinas sobre esta obra... Pe. Leonel Franca, igualmente, concluiu que a Teoria, que defende a filosofia transcendental da afirmação pura, nasceu com este livro e com ele morreu. "Bem the está. É justiça." (em Noções de História da Filosofia, 16a ed.)

Não endosso as opiniões desses dois conceituados críticos. Não fizeram justiça com o trabalho de Patrício Muniz, um dos raros metafísicos profundos de nossa cultura filosófica. Para Leonel Franca as teses filosóficas de Patrício Muniz seriam "verdadeiros enigmas..." Não são. Muito ao contrário, revelam um constante entrosar-se com a Axiologia e seus primeiros princípios. Na Dedicatória a Sua Majestade, Patrício Muniz já reconhecia que "nem o sensualismo, nem o idealismo panteístico podem satisfazer as necessidade do espirito".

"A humanidade nunca deixará de conhecer que há uma realidade superior à matéria, à consciência individual, a todo o finito, principio de si mesma, e para tudo quanto existe: e que é no testemunho desta substância suprema que a razão se desenvolve".

Da Academia Brasileira de Filosofia. 
"A Filosofia desenvolvendo as relações do finito e do infinito, necessariamente da religião é que tira a sua premissa; e querer a religião sem revelação é querer o espírito humano desenvolvido sem ensino exterior, é não conhecer a Humanidade. Se pois o desenvolvimento da razão resulta de um ensino externo, se este ensino é a tradição católica da revelação divina, está claro que a razão tem que se desenvolver à luz da revelação; e a Filosofia, antes de tudo, é o desenvolvimento científico do dogma. Este é o primeiro cânon a estabelecer para a harmonia da ciência e da realidade."

"O dogma é uma realidade de fato, e a verdade num fato; fora uma contradição supô-lo incapaz de uma explicação científica."

Ora, se Patrício Muniz acreditava na possibilidade de a razão atingir cientificamente os dogmas, a Revelação - onde esta é substância de ato, amor, força e, portanto, movimento, energia - como poderia fazer a distinção que pe. Leonel Franca lhe exige?... A Filosofia e a Teologia teriam, obviamente, o mesmo objeto, ou seja, atingir a substância infinita... A Filosofia seria uma ciência transcendental e crítica dos fenômenos da atividade. Compreenderia a Ontologia, estudando o necessário isto é, o existencializado - e a Cosmogonia, cujo objeto seria o possível. Nota-se, claramente, a posição de abertura aos anseios axiológicos onde o valor é um tender-para, um almejar-algo, um ir do como-é ao como-poderia e ao como-deveriaser... É o possivel que se quer atingir... Os animais ficam no como-é... Limitam-se ao que Deus criou... Não fizeram super-mercados onde compram seus alimentos... Colhem-nos diretamente da Natureza. E esta, muitas vezes, identifica-se com Deus. A sua criação passa a receber o seu próprio nome... O homem, ao contrário, foi feito à semelhança divina: possui o dom de criar, assim como Deus... Por isso, há uma realidade natural e uma outra humana, criada pelos homens. E acima dessas, a possível, aquela a ser futuramente existencializada... Toda Axiologia versa sobre este futuro a ser conquistado através do planejamento, da existencialização de novas estruturas.

Patrício Muniz ainda nos fala da Filosofia como ciência crítica, subdividida em Análise, quando se detém nos fenômenos psíquicos, e Arquitetônica, quando trata da Lógica e da Moral. Na sua Teoria da afirmação pura pretendeu abarcar a Filosofia transcendental. A parte crítica ficou como obra futura não realizada, Confessa, ao final do seu livro: "... temos evitado a grande confusão, que produz em muitos filósofos, o negativo-positivo com que temos evitado uma confusão de idéias tão atrasadora na ordem do pensamento, como destruidora na ordem moral". As noções de finito-infinito, positivo-negativo estão sempre presentes em Muniz... Sem as compreender não entenderemos, certamente, a mensagem tão significativa desse filósofo que escreveu em Português, embora tenha estudado Direito em Paris, na Sorbonne, e obtido doutorado em Sagrada Teologia na Universidade Romana...

A concepção que Patrício Muniz tem de substância é rosminiana: "A essência da substância é o ato"; "ato, força e substância são princípios idênticos." "A definição que Rosmini dá da substância satisfaz completamente a esta teoria: substância é o ser no seu atuar primeiro e imanente. Já se vê que, segundo a definição do filósofo italiano, a essência da substância é o ato, nel suo agire primo e imanente" ( $\mathrm{p}$. 3 da Teoria...). 
São dois os princípios que constituem a crítica do sistema filosófico de Muniz: "1ํ - a substância é ato ('vencendo esta tendência do espírito de representar a substância como um ponto no espaço, fizemos ver que o espaço é uma condição afirmativa, senão limitativa da substância...'); $2^{\circ}$ - o nosso pensamento tem sempre a substância por objeto (todas as condições da existência consideradas pelo pensamento não são outra coisa senão a substância)" (p. 7).

Deus é a substância infinita, porque "Deus, substância infinita, ser, são sinônimos" (p. 11). Como a substância é ato, Deus é ação, "poder, inteligência e amor" (p. 19). "O atributo primitivo é o de poder; a inteligência e o amor são atributos dentro do poder".

Sendo poder, possuindo todas as possibilidades, a substância infinita, ou seja, Deus, cria as formas finitas; todavia, nessa criação, ela não se isola dos objetos criados, participa neles, pela energia. Lembra-nos Parmênides, quando afirma que a mesma coisa é ser e pensar o ser... "Porém, a afirmação que é, mas não infinita, é finita; por conseqüência, a afirmação infinita contém em si uma outra afirmação distinta de si, que é a afirmação finita" (p. 69 da Teoria..., no capítulo sobre a criação).

Esta é a noção do ser, dentro do ser: "A afirmação finita está na afirmação infinita, sem contudo ser ela..." (p. 69).

A possibilidade, que é intrínseca da substância infinita, determinará "uma afirmação não infinita, dando individuação distinta da substância infinita..." (p. 69). "A afirmação infinita contém em si uma possibilidade de toda a afirmação, por isso mesmo que ela é infinita e que a negação lhe repugna...". "Toda a afirmação implica a substancialidade". A negação, obviamente, seria a inexistência dessa substância...

"A possibilidade é intrínseca a toda a afirmação. Tirar a possibilidade à afirmação é negá-la, é identificá-la com a negação, mas esta identificação é contraditória; logo, toda a afirmação é possivel". Por outro lado, "o limite da afirmação não afeta a natureza positiva da afirmação, e toda a afirmação, sendo possível, seguese que a afirmação limitada é possível" (p. 63).

Deus é a afirmação absoluta, pura e os objetos são formas limitativas da afirmação e, portanto, possuem atributos, os mesmos, da substância infinita da qual provieram. O ser se afirma infinita e finitamente.

A estética de Muniz segue estes mesmos principios norteadores, pois admite a existencialização do Belo nas coisas em-si, porque, nas coisas belas, há "a identificação do subjetivo no objetivo, porque a beleza de qualquer obra não estará no pensamento" de quem, exteriormente, a percebe, mas "porque a obra de arte, a obra bela, é uma obra que fala de si, que nos deixa na ilusão de que ali há uma consciência, porque ela apresenta o fenômeno físico" de uma consciência (p. 56). O belo é, pois, uma manifestação da substância infinita na finita. "O belo é afirmativo, e todo afirmativo contém-se eminentemente no ser" (p. 55). Assim, pode-se concluir que as coisas belas são existencializações da substância divina; que há um pouco de Deus em tudo aquilo que é belo. Sendo assim, "é, no sentido cristão, que a Filosofia o deve estudar" (p. 55).

Patrício Muniz analisa o problema do bem e do mal. Não haverá o bem em-si, nem o mal em-si: o que existe são relações entre os homens e os bens que os 
completam, que os afirmam... São relações axiológicas certamente. Percebera-as muito antes da Axiologia firmar-se como matéria de primeira grandeza filosófica!... "Já fizemos ver que a noção de bem é uma noção relativa; é um relativo confirmativo..." - na sua linguagem, isto quer dizer que todas as coisas podem concorrer para a melhor afirmação do homem e que se faz necessária uma análise constante para que se saiba em quais circunstâncias uma coisa pode e deve ser substancializada em um bem. O bem "é a relação analítica de toda a afirmação" (p. 90). "O mesmo se há de dizer do mal. Que objeto é esse chamado o mal? O mal é, pois, também um relativo; é a negação entre a objetividade e a afirmação suprema" (p. 90). Vejam que beleza!... É um distanciar-se dos arquétipos supremos, um afastar-se dos valores que tendem, necessariamente, para a afirmação absoluta... Esta ida do homem aos seus fins não é uma contingência, um problemático, mas um determinismo imposto pela própria orientação aos valores válidos, afirmativos, contidos na substância infinita, em Deus. O homem está determinado a afirmar-se absolutamente; só não se afirmará, se não quiser, se opuser uma resistência, não natural, ao seu tropismo inato aos valores que o afirmam e o afirmarão perenemente. $O$ homem pretende chegar à infinitude divina, a existencialização do Belo, à objetivação absoluta de sua total afirmação.

"O mal é a relação de inferioridade em que fica o ato finito a respeito do ato infinito, que o afirma. Ora, a ação de Deus é o que há de afirmativo no finito"; não é, portanto, o negativo, "essa inferioridade" que se pode relacionar com o "tipo supremo". O mal resulta de uma resistência do finito à ação divina" (p. 90). "Cai-se em contradição responsabilizando pelo mal a ação divina", porque Deus "é causa imediata de tudo o que existe, de tudo o que é". Visto que tudo é bem, "Deus é causa imediata só do bem". "Deus, diz Santo Agostinho, não é autor do mal, porque ele não é causa da tendência ao não ser" (p. 90).

Patrício Muniz encontra a explicação para os fenômenos de ordem moral que levam alguém a ser o instrumento do mal: a fatalidade... Não seria mais fácil deixar-nos passivos para que a ação divina atuasse sobre nós?... Se somos parte da substância infinita, a ela nos deveríamos entregar inteiramente.

A liberdade é um fato, e aparece, no finito, como possibilidade de resistência à ação de Deus. Essa liberdade, envolvendo muitas possibilidades, pode levar o homem a "conservar-se aquém do intuito infinito". E é nisto em que consiste o mal. Disto poder-se-ia concluir toda uma ética baseada nos fundamentos arquétipos dos valores.

Meditemos com Patrício Muniz: - "O negativo não é o infinito: é a sua negação..." E o que o homem deseja, e para o que foi destinado, é a sua substância infinita, Deus, síntese de todos os arquétipos, de todos os valores axiologicamente válidos.

À exclamação de pe. Leonel Franca, em relação ao autor da Teoria da afirmação pura, cheia de prepotências e preconceitos, "E isto chama-se filosofar!", retruco: Chama-se.

Patrício Muniz foi um dos primeiros, no Brasil, a seguir a filosofia alemã, referindo-se, comumente, a Krause. Procurou suas armas de polêmica filosófica na escolástica medieval. Leonel Franca foi categórico ao afirmar que de escolástica Pa- 
trício Muniz "não entendeu migalha"... Acredito que de Patrício Muniz quem nada entendeu foi o Leonel Franca...

Deixemos esta polêmica e voltemos à afirmação que precisa ser bem conceituada para que se faça melhor entendida. O homem é o objeto da afirmação. Não é a vida na sua totalidade. Do homem o que se valoriza é a sua consciência, o seu eu racional e criativo... O homem é, sem dúvidas, o centro de todos os valores... Se uma doença aparecer nos cachorros, capaz de contaminar os humanos levando-os à morte, iremos para as ruas caçar todos os cachorros e matá-los. Porque entre afirmar os cachorros ou os homens, optar-se-ia, obviamente, pela raça à qual pertencemos. Não há uma axiologia das galinhas, mas sim, aquela que resulta em bens para os homens...

Afirmar é favorecer as relações entre as necessidades humanas e os bens capazes da satisfação das mesmas. Valor é relação, não é um ser-em-si... As estruturas axiológicas são sempre relacionais...

Por outro lado, a Axiologia exige a constante divisão entre o como-é e o comodeveria e o como-poderia-ser. Deus deu-nos o como-é e mais a capacidade do evoluir, do optar, do estruturar-se, do criar novas estruturas num como-poderia-ser mais profícuo. O planejamento, que se existencializa através da fé, permite-nos, racionalmente, atingir sempre futuros cada vez mais afirmativos... Todavia, o homem luta contra a natureza que evolui, que o leva, infalivelmente, ao seu não-ser individual... Deus, sendo afirmação pura, não pode compactuar com a morte, com o desagregar-se num evoluir para o nada. Para tanto, transcende ao problemático de uma existência futura num mundo exclusivamente espiritual. A vida eterna faz parte do conteúdo da idéia de Deus, plena de afirmação.

A Moral, matéria eminentemente axiológica, terá que levar em conta a afirmação como seu fundamento. Por isso, pode-se concluir da imoralidade do como-é, desse evoluir do ser-homem ao seu nada. Moral será o lutar-se contra isto, contra 0 que nos nega ou possibilita a negação. As guerras são imorais, por este motivo. A velhice, as doenças são imoralidades. Mesmo ditas "naturais", são contra a afirmação, logo, imorais. O homem peca por omissão quando não age no sentido do afirmar-se perenemente. Um governo que não destina verbas para as pesquisas científicas, que poderão descobrir remédios que nos salvarão da morte, faz-se imoral pela falta de visão axiológica ao como-deveria-ser-humano... Entre o como-é, realista, que nos mostra uma realidade que nos nega, infalivelmente, e o como-deveria-ser, onde aparece o homem imortal, que não se desgasta, que é e pretende sempre-continuar-sendo, vai a distância do realista ao problemático. Deus é, em seu conteúdo, afirmativo-problemático, porque destina-se ao ser sempre constante, não evolutivo, não natural... O natural é imoral. Imoral é não lutar-se para atingir a afirmação plena...

Qualquer problema axiológico precisa levar em conta o metabolismo que existe entre os valores. Precisamos resolvê-los todos. Porque a não-resolução afirmativa de um afetará a resolução dos demais. A afirmação faz o homem tender para a plenitude da realização de todos os valores, sejam eles de quais naturezas forem... $\mathrm{O}$ belo, também, terá que ser analisado à luz da afirmação. Uma paisagem que nos mostra um pântano, sombrio, de águas turvas e fétidas, onde a vida não se manifesta, será mais feia do que aquela plena de vida de águas límpidas, vegetação vi- 
çosa, onde peixes e pássaros estejam presentes... O belo está mais perto dos bens que favorecem a afirmação do que aqueles que a agridem... A análise axiológica envolve, concomitantemente, a presença de todos os bens-valores... Onde houver maior afirmação haverá mais belo, mais justiça, mais fartura, menos doenças, menos mortes, menos velhice, mais essência divina...

A afirmação exige a verdade-estatística, isto é, que a maior quantidade de vida humana seja afirmada dentro do seu contexto de possiveis axiológicos. Entre dois países em guerra mortal, a Axiologia sugerirá a paz entre as nações beligerantes porque o entrosamento, o estruturar-se será mais afirmativo do que a carnificina das lutas. No entanto, os planejamentos deverão sempre levar em conta os limites da boa e racional afirmação... A verdade-estatística, muitas vezes, exigirá a negação de partes para a maior afirmação do todo, como quem tira, corta e joga no lixo o câncer que afetava o organismo... Muito cuidado se terá com os limites ideais da população do planeta Terra. É melhor que já se planeje o número ideal dos habitantes terrestres do que se estar facilitando os nascimentos além daqueles limites ideais que poderão, realmente, afirmar o homem. Além destes, o que se verificará será uma loucura de negações irracionais...

$\mathrm{O}$ afirmar resulta de um constante perquirir, planejar, analisar. Muitas vezes, pensa-se estar afirmando, quando se está negando...

Sendo Deus a suprema afirmação, precisará sempre ser analisado no seu conteúdo axiológico... Imoral é o que nega o homem. Pecar é distanciar-se da afirmação. A consciência é e procurará sempre continuar sendo, mesmo problematicamente, numa vida futura depois da morte física... Em Deu's o homem não morre, não se nega... Por isso, o homem, feito à Sua semelhança, procurará sempre tender para Deus na ânsia de perenemente afirmar-se... 